\title{
A Teaching Case Study: Roxy Music Limited
}

Yvonne P. Shanahan, (E-mail: yvonne.shanahan@canterbury.ac.nz), University of Canterbury, New Zealand Morris W. Shanahan, (E-mail: shanahanm@cpit.ac.nz), Christchurch Polytechnic Institute Technology, New Zealand

\section{BACKGROUND}

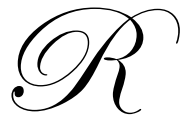

oxy Music Limited is a wholesale supplier of Compact Discs (CDs), Music Cassettes, Videos and, more recently DVDs, in the New Zealand music and entertainment market. All products are imported from Germany, the United Kingdom, the United States of America or Holland. Product arrives in boxes of 1,000 units. For the purpose of this case, we are focusing on CD sales.

\section{CUSTOMERS}

Roxy Music distributes its products to a variety of customers, and the major difference between these customers is the volume of product which they order. Roxy Music has one large customer which is a national chain (not only of Roxy Music's product) - Warehouse Music. Warehouse Music sells approximately $30 \%$ of the retail sales volume. This customer always buys in large quantities. For the Top 20 chart hits, they would purchase in volumes of a minimum 1,000 units often up to 10,000 units and they would purchase these quantities in either one, two or three orders, depending on the success of the charted album. They would sell 30,000 units if an Album went platinum. Warehouse Music always pay on time $-20^{\text {th }}$ of the Month following and require no extra administrative effort.

At the other end of the continuum, there are a number of small music stores throughout New Zealand. $40 \%$ of these stores are in the South Island, while 60\% are in the North Island. These customers tend to be very risk averse at being left with obsolete product. In the music industry it does not take long for an album to become a non-chart hit and therefore excess inventory is a concern, both to Roxy Music and the retailers. The average number of units per order is 10 units. If an album proves to be more successful they may order small amounts for up to 20 weeks with many orders per week. They are also notoriously bad payers and most often each order is paid 90 days later. This requires at least 15 extra administrative minutes a month of follow up per customer as well as working capital being tied up. In total these stores sell around $20 \%$ of the total market and an individual store would sell up to 500 units.

Roxy Music also has two medium-sized customers: Music Haven (North Island) and the Music Store (South Island). These two customers sell $25 \%$ of the market respectively. Although these stores also buy in large quantities relative to the smaller stores, they still tend to make smaller orders due to the risk of obsolescence which the large customer can offset against its vast array of other products. For Top 20 chart hits they tend to make a large order up front, of 10,000 units, then await the chart success and order each week in volumes of 1,000-5,000 units - over the next 6-10 weeks. In total for a platinum album they would order 25,000 units. These two firms usually take 60 days to pay their accounts.

Despite these distinctive customer groups, Roxy Music applies the same approach to all its customers. This is because the CEO of Roxy Music was once herself a small retailer and has a passion for giving all customers an equal opportunity to succeed in the competitive market place.

In the music industry the product speaks for itself. Marketing activities involve promotions with radio. Good radio coverage usually ensures a chart spot and then retailers want the product. More marketing may also be done in store with artist signings etc. Once the marketing has been successful, in-house sales people literally wait for the phone to ring, but are also actively encouraged to "hard-sell" if necessary to all customers equally, and receive a commission. Roxy Music does not give discounts, and also pays freight (a long standing arrangement with the large client which the CEO maintains for all her clients). 


\section{DISTRIBUTION}

Roxy Music has a large warehouse in an Auckland ${ }^{1}$ suburb. Although there is an adequate stock control system, many manual processes still occur. The warehouse receives the orders from Head Office at the end of each business day (the computer system at Head Office is not linked to the Warehouse system). These orders are then processed the next day. Where an order is for 1,000 units or more it is relatively straight forward. Each 1,000 unit box is picked from the shelf, labelled and then collected by the courier firm. This process takes 15 minutes per box.

Roxy Music has negotiated a contract with a large courier company at a rate of $\$ 200$ per "unaltered" 1,000 unit box. However, they also have a minimum charge of $\$ 50$ per small box (either $5 \mathrm{~kg}$ or an A4 photocopy box either size or weight applies) between Auckland and a South Island firm. The equivalent rate is $\$ 35$ for a courier parcel in the North Island.

Where the order is for less than 1,000 , the process is much slower. A 1,000 unit box must be opened. The number of units must be manually selected and the balance left in the box is recorded (open boxes have also proven to be problematic with theft - usually 10 units per box go missing). The small order then needs to be manually repacked. This process takes 2 hours per order. The order is then couriered in the usual way.

\section{THE ISSUES}

Despite the egalitarian nature of the current CEO, the financial controller at Roxy Music has become concerned about the different levels of support that the customer groups require. The controller is also questioning the nondiscounting and freight policy. Currently, management has no basis for identifying customers that generate high profits or those that do not generate enough revenues to cover the expenses to support them.

\section{EXERCISES}

You are the finance manager of Roxy Music and are a member of a management team set up to assess the profitability of the customer accounts. We are going to use an example of an album which goes Platinum that is 100,000 units nationwide. It goes platinum in a period of 10 weeks. The wholesale sales price per CD is $\$ 14$ dollars. The product cost is $60 \%$ of this. Roxy Music also has to pay Australian Performing Rights Association (APRA) (for the musicians) at $3.5 \%$ of gross.

Orders are undertaken only by phone. A log has shown that the medium and large clients take 5 minutes, while small clients take 45 minutes. This is due to them discussing all the problems they are having with their small businesses. Telephone sales personnel are paid for 40 hours a week and earn $\$ 30,000$ per annum. Packing and shipping an order takes 15 minutes for a 1,000 unit box but it takes 2 hours when it needs to be repackaged into smaller containers and then couriered. Warehouse staff earn on average $\$ 12.50$ per hour. Administrative salaries are $\$ 30,000$ also.

\section{REQUIREMENTS}

1. Before the next management meeting, you are to calculate the profitability of a representative customer from each group.

2. As a result of the above analysis, management then requests you to hold a focus group with some representative small customers. The purpose of the focus group is to discuss future arrangements with these clients. Establish the issues you will address at this focus group. In addition report back to management any other issues which may need to be addressed by the firm.

\footnotetext{
${ }^{1}$ New Zealand's largest city.
} 


\section{A SUGGESTED SOLUTION}

The following tables provide the master spreadsheet for the customer profitability calculation as requested in question 1 (Table A) and supporting calculations (Tables B and C).

\section{A. Profitability}

\begin{tabular}{|c|c|c|c|c|c|c|}
\hline \multirow{2}{*}{$\begin{array}{l}\text { Customer } \\
\text { Sales }\end{array}$} & \multicolumn{2}{|c|}{ Warehouse } & $\begin{array}{l}\text { Small } \\
\text { South } \\
\text { Island }\end{array}$ & $\begin{array}{l}\text { Small } \\
\text { North } \\
\text { Island }\end{array}$ & \multicolumn{2}{|c|}{ Music Haven } \\
\hline & & & & & & \\
\hline Units & & 30,000 & 500 & 500 & & 25,000 \\
\hline Number of Orders & & 3 & 50 & 50 & & 4 \\
\hline Sales Price & & $\$ 14$ & $\$ 14$ & $\$ 14$ & & $\$ 14$ \\
\hline Total Revenue & $\$$ & 420,000 & $\$ 7,000$ & $\$ 7,000$ & $\$$ & 350,000 \\
\hline Cost of Goods sold (60\%) & $\$$ & 252,000 & $\$ 4,200$ & $\$ 4,200$ & $\$$ & 210,000 \\
\hline Gross Profit & $\$$ & 168,000 & $\$ 2,800$ & $\$ 2,800$ & $\$$ & 140,000 \\
\hline \multicolumn{7}{|l|}{ Other Customer Costs } \\
\hline APRA $(3.5 \%)$ & $\$$ & 14,700 & 245 & 245 & $\$$ & 12,250 \\
\hline Ordering & $\$$ & 4 & $\$ 586$ & $\$ 586$ & $\$$ & 5 \\
\hline Packing & $\$$ & 94 & $\$ 1,250$ & $\$ 1,250$ & $\$$ & 78 \\
\hline Freight & $\$$ & 6,000 & $\$ 2,500$ & $\$ 1,750$ & $\$$ & 5,000 \\
\hline Administrative Time & $\$$ & - & $\$ 587$ & \$ 587 & $\$$ & 31 \\
\hline Total Customer Costs & $\$$ & 20,798 & $\$ 5,168$ & $\$ 4,418$ & $\$$ & 17,365 \\
\hline Net Profit & $\$$ & 147,202 & $-\$ 2,368$ & $-\$ 1,618$ & $\$$ & 122,635 \\
\hline Net Profit Percentage & & $35.05 \%$ & $-33.82 \%$ & $-23.11 \%$ & & $35.04 \%$ \\
\hline
\end{tabular}

\section{B. Calculations}

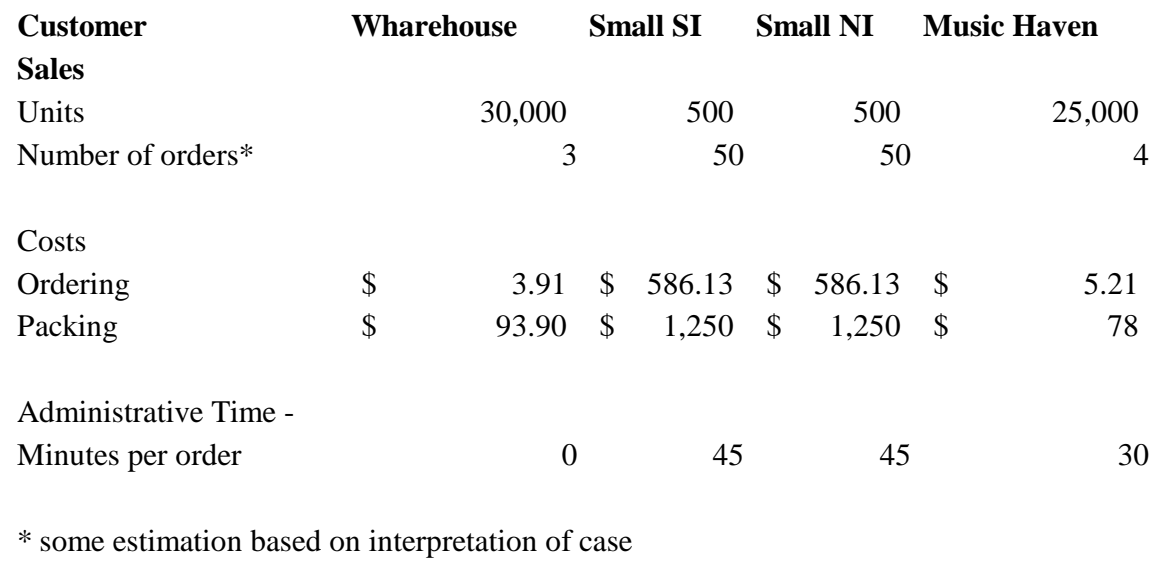

(NB. The telephonist time is deemed to be at capacity that is 48 weeks and 40 hours per week. Clearly, this is a simplifying assumption as actual hours on the phone would unlikely be $100 \%$.) 


\section{Activity Based Costing Calculations}

\begin{tabular}{|c|c|c|}
\hline \multicolumn{3}{|l|}{ ABC Calculations } \\
\hline \multicolumn{3}{|l|}{ Cost of order } \\
\hline Salary & $\$$ & 30,000 \\
\hline Number of hours per annum & & 1,920 \\
\hline Cost per hour & $\$$ & 15.63 \\
\hline \multicolumn{3}{|l|}{ Cost of packing } \\
\hline 1000 unit box & & 15 mins \\
\hline Hourly rate & $\$$ & 12.50 \\
\hline Cost per unit box & $\$$ & 3.13 \\
\hline Partial box & & 2 hours \\
\hline Hourly rate & $\$$ & 12.50 \\
\hline Cost per partial box & $\$$ & 25.00 \\
\hline \multicolumn{3}{|l|}{ Freight $5 \mathrm{~kg}$ or minimum } \\
\hline South Island & $\$$ & 50.00 \\
\hline North Island & $\$$ & 35.00 \\
\hline \multicolumn{3}{|l|}{ Debtor follow up } \\
\hline Salary & $\$$ & 30,000 \\
\hline Yearly hours & & 1,920 \\
\hline Hourly rate & $\$$ & 15.63 \\
\hline Per 15 minutes & $\$$ & 3.91 \\
\hline
\end{tabular}

\section{ISSUES FOR FOCUS GROUPS - CUSTOMERS}

1. Encourage larger orders - this may be achievable by allowing the smaller firms to have a sale or return policy for a period of $4-6$ weeks.

2. Establish internet ordering.

3. Update computer systems so that small customers can order direct to the warehouse.

4. Review the freight policy. Small clients should have to pay freight on board.

5. Discuss payment plans so that orders are paid either cash on delivery or offer an incentive through a prompt payment discount.

\section{OTHER ISSUES}

1. Improvements are needed in the computer systems. The head office computer needs to be linked to the warehouse system so that the manual delivery of orders can cease.

2. Freight - look at renegotiating where the small customer is not so disadvantaged - this may cost slightly more for large clients but would improve the contribution for small clients.

3. Improve the credit control policy. Insufficient effort is being made to follow up payment of small clients. 